\title{
Ecohydrology of an outbreak: mountain pine beetle impacts trees in drier landscape positions first
}

\author{
Kendra E. Kaiser, ${ }^{1,2 *}$ Brian L. McGlynn ${ }^{1,2}$ and Ryan E. Emanuel ${ }^{3}$ \\ ${ }^{1}$ Montana State University, Watershed Hydrology Lab, Bozeman, MT, 59717 USA \\ ${ }^{2}$ Duke University, Division of Earth and Ocean Sciences, Nicholas School of the Environment, Durham, NC, 27708 USA \\ ${ }^{3}$ North Carolina State University, Department of Forestry and Environmental Resources, Raleigh, NC, 27695 USA
}

\begin{abstract}
Vegetation pattern and landscape structure intersect to exert strong control over ecohydrological dynamics at the watershed scale. The hydrologic implications of vegetation disturbance (e.g. fire, disease) depend on the spatial pattern and form of environmental change. Here, we investigate this intersection at Tenderfoot Creek Experimental Forest (TCEF), Montana, with a focus on the mountain pine beetle (Dendroctonus ponderosae) epidemic currently affecting the Rocky Mountains. We calibrated QuickBird remote sensing imagery with a leaf-level spectral library of local vegetation. We used this spectral library to determine diagnostic vegetation indices for differentiating stages of beetle infestation within the $37 \mathrm{~km}^{2}$ TCEF watershed. These indices formed the basis of a three-component mixing model to establish the extent and magnitude of beetle infestation across the TCEF watershed. We compared disturbance patterns with spatially distributed topography and vegetation variables derived from a light detection and ranging-based digital elevation model of TCEF. We determined that certain landscape characteristics (low vegetation density, south-facing slopes, steep slopes, locations with small contributing areas and locations with lower values of the topographic wetness index) were significantly more likely to exhibit the effects of beetle infestation. Our efforts to monitor vegetation mortality across space and time provide a context for assessing landscape susceptibility to initial mountain pine beetle infestation and how outbreak (i.e. landscape scale infestation) patterns may affect watershed ecohydrology via altered water and biogeochemical cycles. Copyright (C) 2012 John Wiley \& Sons, Ltd.
\end{abstract}

KEY WORDS mountain pine beetle; disturbance; vegetation patterns; mountain hydrology; emergent properties; ecohydrology; remote sensing; landscape structure

Received 17 December 2011; Revised 14 May 2012; Accepted 16 May 2012

\section{INTRODUCTION}

Ecohydrology relates the spatiotemporal interaction of hydrologic and ecologic dynamics across scales (Rodriguez-Iturbe, 2000). Understanding how these processes interact is important for development of effective strategies and tools for sustainable resource management. Ecosystem disturbances, including mountain pine beetle (MPB) outbreaks, provide a unique opportunity to analyse these interactions because of the mosaic of land-cover change that discrete, MPB disturbance events can impart on the landscape (Turner, 2005). Patterns of change and ecosystem response to those changes can be used to develop a more mechanistic understanding of interactions and feedbacks between hydrological and ecological processes.

The current MPB outbreak is the greatest biological cause of mature pine mortality in western North America (Safranyik and Carroll, 2006; Shore et al., 2006). The MPB is estimated to have affected approximately 17.5 million ha in Canada since the current outbreak began in the late 1990s (British Columbia Ministry of Forests and Range, 2011). MPB has impacted 3.5 million ha in the United

*Correspondence to: Kendra E. Kaiser, Nicholas School of the Environment, Duke University, USA. E-mail: kendra.kaiser@gmail.com
States, accounting for nearly $75 \%$ of all tree mortality caused by insects and disease during 2010 (Gannon and Sontag, 2011). The location of MPB infestation and resulting tree mortality across the landscape are a result of interacting variables. Some of these include forest characteristics (e.g. age-class structure and stand characteristics), climatic conditions and variability, MPB population dynamics and land management practices (Taylor et al., 2006). The key environmental drivers of this epidemic are interconnected, making them difficult to partition at the landscape scale.

The extent of an MPB outbreak is determined primarily by host availability, which is predominantly lodgepole pine (LPP; Pinus contorta) and by MPB population dynamics. Over the past 40 years, the range of MPB has expanded to higher elevations and latitudes likely because of increased minimum winter temperatures and increased summer temperatures (Taylor et al., 2006). Additionally, the area burned by wildfire has decreased since the early 20th century because of fire suppression, leaving behind large areas of suitable, even-aged hosts for MPB infestation. Thus, the large availability of mature lodgepole stands, along with increased stress on the species from climate change and fire suppression, has contributed to the expansion of MPB habitat (Kurz et al., 2008).

Because infestation is partially a function of forest structure and physiological characteristics of host trees, it is also inherently dependent on landscape factors that affect the 
distribution and stress experienced by forest vegetation. The spatial patterns of relief lead to differences in abiotic factors, such as soil development, which influence vegetation distributions across the landscape (Turner, 2005). Additionally, topographic structure mediates the lateral redistribution of water (Jencso et al., 2009) and the land surface energy balance, giving rise to temporal complexity in ecological processes associated with vegetation (Emanuel et al., 2011), soils and temperature (Riveros-Iregui et al., 2011a). These interacting dynamics can inhibit understanding of the progression of outbreaks and the resulting spatial patterns of disturbance that they impart on the landscape.

The distribution of MPB affects the structure of forest ecosystems over a range of spatial scales by impacting individual tree and forest stand characteristics across the landscape (Shore et al., 2006). The extensive tree mortality resulting from mountain pine beetle outbreaks can have strong impacts on fluvial dynamics (e.g. runoff) and landatmosphere exchange of water and carbon from watersheds. Boon (2007) and Pugh (2011) both found increases in snow accumulation under stands of dead MPB infested trees, which could result in greater water yield during annual snowmelt. Furthermore, MPB induced tree mortality could shift forest ecosystems from carbon sinks to carbon sources by decreasing carbon uptake by photosynthesis and increasing carbon release from decaying trees (Dennison et al., 2010; Kurz et al., 2008). Stands that undergo extensive die-off can also exhibit increased nutrient export. Clow et al. (2011) observed increases in total nitrogen $(\mathrm{N})$ and phosphorous $(\mathrm{P})$ in stream water chemistry and increases in available $\mathrm{N}, \mathrm{NH}_{4}$ and $\mathrm{NO}_{3}$ in the soil beneath trees killed by MPB. Therefore, MPB initiated forest die-off has implications for green house gas emissions, water quality, and ecosystem scale biogeochemical cycling. Quantifying where and when trees are dying can also provide insight into mechanisms and factors contributing to differential landscape susceptibility to disturbance, allowing for identification of at risk locations. This necessitates mapping and quantifying the extent of MPB induced tree mortality and understanding the underlying mechanistic thresholds. Both of these objectives were noted as key research priorities in a recent review (Allen et al., 2010). We suggest that remote sensing could provide an ideal starting point for quantifying tree mortality accurately across large spatial extents in threatened forests worldwide.

\section{Mountain pine beetle biology and host response}

The MPB (Dendroctonus ponderosae) is an insect indigenous to western North America. It inhabits lodgepole, ponderosa (Pinus ponderosa), sugar (Pinus lambertiana), whitebark pine (Pinus albicaulis), and western white pines (Pinus monticola) by boring and tunnelling through the bark into the phloem where they feed and lay their eggs. The life cycle of the MPB includes migration from dead brood trees, colonization of new hosts and development. As they bore through the bark of the tree, the beetles breed and transfer a pathogenic fungus that they carry. Beetle infestation and the associated blue stain fungus (Ophiostoma spp.) can kill a tree within 13 months by disrupting the flow of water and pitch (Amman et al., 1985).
Conifers have several physiological defence mechanisms to resist beetle infestation. The cells in the cortex of the tree contain monoterpenes that are toxic to MPB larvae and eggs and inhibit fungal growth. The monoterpenes increase in concentration as vascular cells undergo necrosis in cells surrounding the blue stain fungus (Raffa and Berryman, 1983). Trees also produce liquid resin that can kill or repel the beetles in addition to preventing oviposition in the beetle galleries and confining and killing the fungi (Raffa and Berryman, 1983). The resulting presence of pitch tubes on the bark of the tree creates a visible sign of conifer response to the beetle infestation. Trees that are 60-160 years old have been noted as being the most susceptible to infestation because of the phloem thickness (Amman, 1972); however, host resistance has also been shown to increase with age (Safranyik et al., 1975) to about 100 years (Peterman, 1978).

Mountain pine beetles have two mechanisms for overcoming tree defences. The first is to attack the tree en masse by emitting pheromones that recruit other beetles to a single tree. By concentrating attacks on specific trees, the beetles overwhelm the trees' defence mechanisms. Second, spores from the blue stain fungus that the beetles carry are deposited in the phloem and xylem of the tree, penetrating and killing the cells (Safranyik et al., 1975). Growth of the fungus stops the production and movement of resin in the tree and disrupts transpiration (Mathre, 1964). This leaves the tree unable to translocate water and nutrients because of the blockage by the developing brood and fungus in its phloem and xylem (Raffa and Berryman, 1987).

When beetles emerge from host trees, they undertake multiple modes of dispersal (Raffa et al., 2008), allowing them to infest trees across a broad range of landscape positions encompassing a variety of host densities and physiologies. Beetles can emerge and attack the nearest host; they can attack after flying some distance (Shepherd, 1966; Safranyik and Carroll, 2006) or be caught in warm convective winds that can transport them over $20 \mathrm{~km}$ (Furniss and Furniss, 1972). Dispersal mechanisms can affect spatial pattern of MPB infestation; however, beetles disperse broadly across the landscape, exposing all landscape positions to beetle infestation. Although multiple modes of dispersal lead to beetles reaching many landscape positions, outbreaks have been found to commonly develop in well-distributed stands of large diameter LPP (Amman et al., 1985).

Visible signs of MPB infestation in the forest canopy occur in the spring and summer following the initial infestation. The physiological changes that occur in response to infestation cause the tree crown to change colours. In the first stage (green stage), the tree is infested but remains green throughout the growing season. The following spring, the tree fades to yellow then to red (red stage), and within 3 years of attack, all of the needles have dropped (Figure 1; Wulder et al., 2006).

\section{Remote sensing}

As the spatial extent of affected area increases in the Rocky Mountains, timely information on the scope and severity 


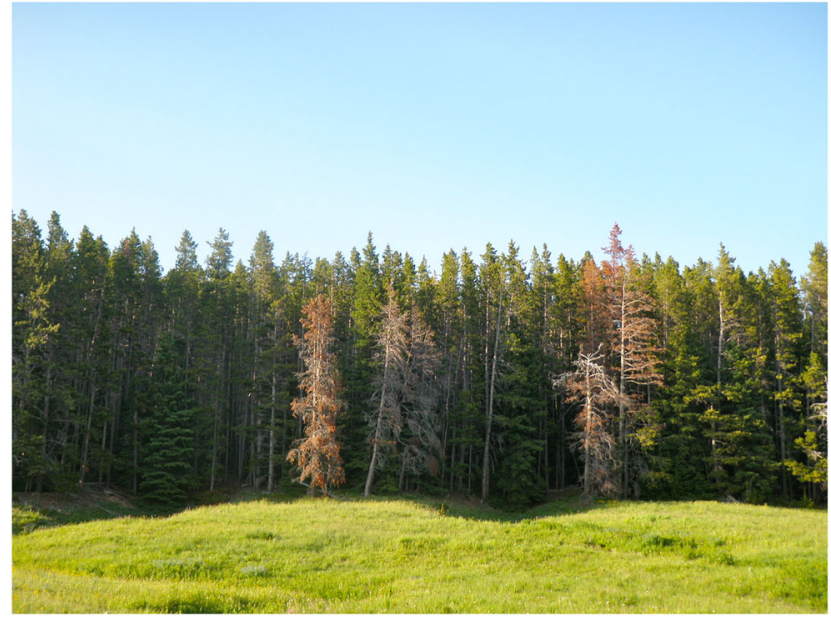

Figure 1. Green-stage, red-stage and dead lodgepole pine (LPP) trees adjacent to a meadow at Tenderfoot Creek Experimental Forest, Montana, USA show the colour change in LPP with different stages of mountain pine beetle infestation.

of the outbreaks is critical for forest management. The severity of these outbreaks has brought increased attention to methods that can rapidly map and assess beetle infestation. High resolution remote sensing offers the ability to map these disturbance events (Coops et al., 2006; Wulder et al., 2006; Hilker et al., 2009), which happen over the course of years, unlike pulse events such as fires and clear cuts, allowing us to observe their progression from initial infestation.

Remote observations can be used to infer ecosystem impacts (e.g. water quality and availability, nutrient cycling, land-atmosphere exchange) of the MPB and lead to a better understanding of how resource management and human-induced change (e.g. climate change) affect these systems. Although remote sensing provides a way to quantify and map MPB-induced tree mortality, the methods used to identify attacked trees are still under development. In this study, we applied a three-component mixing model of spectral reflectance indices to a high-resolution, multispectral (QuickBird) image fused with LiDAR (light detection and ranging) in a subalpine watershed in central Montana to analyse the emergent MPB outbreak. Our objective was to quantify not only the spatial extent of the infestation but also to analyse spatial patterns of the infestation using topography and vegetation indices. If the mechanism of tree die-off is water stress initiated by MPB infestation and the associated blue stain fungus, then one would expect that trees in drier landscape positions would exhibit disproportionate mortality in early phases of infestation. We evaluated this hypothesis by comparing landscape and forest structure indices associated with each tree infestation stage early in an infestation.

\section{METHODS}

\section{Site description}

Tenderfoot Creek Experimental Forest (TCEF) is a $22-\mathrm{km}^{2}$ watershed located in the Lewis and Clark National Forest in the Little Belt Mountains of central Montana (Figure 2). The watershed is a forested subalpine site ranging in elevation from 1985 to $2421 \mathrm{~m}$. The site has been described as an even-aged LPP forest (Mincemoyer and Birdsall, 2006), with interspersed subalpine fir (Abies lasiocarpa) and Engelman spruce (Picea engelmannii), containing small riparian areas ( $4 \%$ of the watershed) and upland meadows (Emanuel et al., 2010; Jencso et al., 2010). TCEF is comprised of seven heavily instrumented subwatersheds that form the headwaters of Tenderfoot Creek, a tributary of the Smith River within the Upper Missouri River basin (Jencso and McGlynn, 2011).

Mean annual precipitation at TCEF is $880 \mathrm{~mm}$, with more than $70 \%$ in the form of snow (McCaughey, 1996). The geology is granite gneiss, shale, quartz porphyry and quartzite (Farnes et al., 1995). In the riparian zones, the major soil group is clayey Aquic Cryoboralfs (Holdorf, 1981), the groundwater tables are usually at or near the soil surface and soil depths range from 0.5 to $2.0 \mathrm{~m}$ (Jencso et al., 2009). Loamy Typic Cryochrepts are found on the hillslopes (Holdorf, 1981), with soil depths ranging from $0 \cdot 5$ to $1 \mathrm{~m}$ (Jencso et al., 2009).

Tenderfoot Creek Experimental Forest underwent patch cutting and stand thinning in two of the subwatersheds (764 ha total) in 2000 (Figure 2, McCaughey et al., 2006); the remainder of TCEF has never been harvested, and it has been largely free of fire since the late 1800s (Hardy et al., 2006). Prior to 2009, the Lewis and Clark National Forest (where TCEF is located) was relatively free of MPB

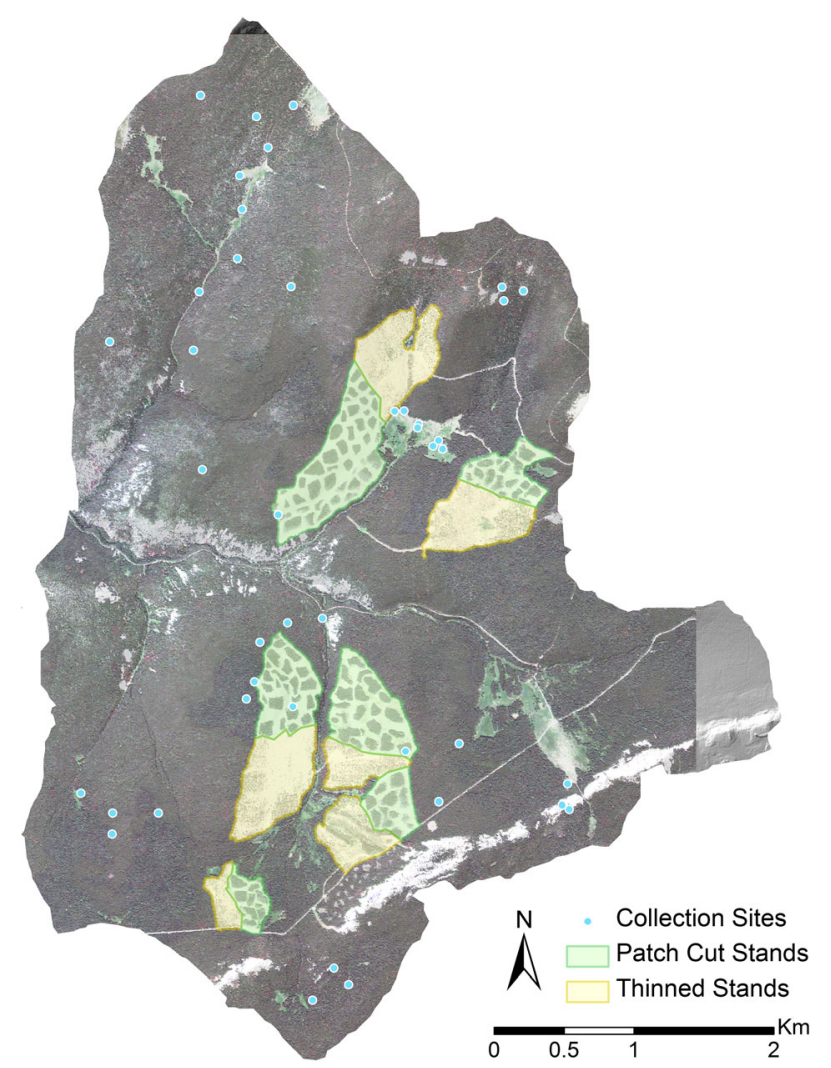

Figure 2. QuickBird image of Tenderfoot Creek watershed study site $\left(22 \mathrm{~km}^{2}\right)$ within the Tenderfoot Creek Experimental Forest. Sites for collection of vegetation spectral signals are shown. Patch cut and thinned stands are delineated showing the managed areas not included in the analysis. 
(Gannon and Sontag, 2009), making it an excellent site to study spatial patterns during an emerging beetle outbreak.

\section{High spatial resolution remote sensing}

A QuickBird image was acquired for TCEF on 17 July 2010. The QuickBird imagery includes a $0.65 \mathrm{~m}$ resolution panchromatic image $(405-1053 \mathrm{~nm})$ and a $2.62 \mathrm{~m}$ resolution multispectral image with four bands: blue $(450-520 \mathrm{~nm})$, green $(520-600 \mathrm{~nm})$, red $(630-690 \mathrm{~nm})$ and near infrared $(760-900 \mathrm{~nm})$. We performed orthorectification and georectification of the multichromatic QuickBird image. The rectifications were completed using a $1-\mathrm{m}^{2}$ digital elevation model derived from LiDAR data that were obtained in September 2005 by the National Center for Airborne Laser Mapping (NCALM, Berkeley, CA). To decrease spectral noise from soils, the Soil Adjusted Vegetation Index (SAVI; Huete, 1988) was calculated for the image, and pixels with values of less than 0.35 were removed from the analysis. The SAVI was calculated as

$$
\mathrm{SAVI}=\left(\frac{\mathrm{NIR}-\mathrm{Red}}{\mathrm{NIR}+\mathrm{Red}+\mathrm{L}}\right)(1+\mathrm{L})
$$

where NIR is the near infrared value of each pixel from the QuickBird image, Red is the red band value and $\mathrm{L}$ is 0.5 , which is representative of an intermediate vegetation density (Huete, 1988). To decrease any residual effects of the management practices on the analysis, the patch cut and thinned locations were delineated, buffered by $3 \mathrm{~m}$ and removed from the analysis. The corrected image was resampled to a $1 \mathrm{~m}^{2}$ pixel size to compare infestation stage with other spatial data available for TCEF.

We calculated multiple landscape metrics from the LiDAR data to characterize topographic and vegetation structure. Vegetation height was calculated as the difference between the first (canopy top) and final returns (bare earth) following Emanuel et al. (2010). Vegetation height pixels under $3 \mathrm{~m}$ were removed from analysis to decrease the spectral noise from herbaceous ground cover. Forest density was calculated as the frequency of $1-\mathrm{m}^{2}$ pixels containing trees (i.e. vegetation height $>3 \mathrm{~m}$ ) in a $100 \mathrm{~m}^{2}$ moving window. The bare earth digital elevation model was resampled to $10-\mathrm{m}^{2}$ resolution to reduce the effects of microtopography and used to calculate the upslope accumulated area (UAA), the topographic wetness index (TWI), slope, aspect, elevation and annual insolation. The UAA represents the upslope area draining to a given point and is a surrogate for relative water availability (Jencso et al., 2009). TWI is another metric of water availability that incorporates local slope as well as area accumulation:

$$
\mathrm{TWI}=\ln \left(\frac{a}{\tan \beta}\right)
$$

where $a$ is UAA and $\tan \beta$ is local slope, which estimates the hydraulic gradient at each point (Beven and Kirkby, 1979). Potential incoming solar radiation $\left(\mathrm{kwh} / \mathrm{m}^{2} /\right.$ year; Oke, 1988; Wilson and Gallant, 2000, Boehner and Antonic, 2009) was calculated in the System for Automated
Geoscientific Analyses by accumulating the 6-h values with a solar constant of $1367 \mathrm{~W} \mathrm{~m}^{-2}$. Insolation integrates multiple variables into one measure of energy input from solar radiation on the basis of slope, elevation, aspect and solar irradiance.

\section{Field methods}

We measured and recorded over 700 samples of vegetation spectral characteristics with a handheld spectrometer (Apogee Instruments Model PS100, Logan, UT) during the fall of 2010 (5-29 September) throughout TCEF (Figure 2). Spectral samples of needles were taken from 40 locations with varying slope, aspect, UAA and elevation. The samples were collected from the lower branches of LPP of every infestation status and across species including subalpine fir and Engelmann spruce. All samples were classified by species, colour and infestation status if the sample was LPP.

\section{Mixing model}

We developed a three-component mixing model to assess the spatial extent of infestation and to determine correlations between infestation and various landscape variables. Three-component mass balance mixing models are widely used in the environmental sciences including use to determine the fraction of various water sources contributing to storm runoff (DeWalle et al., 1988; Ogunkoya and Jenkins, 1993; Burns et al., 2001; McGlynn and McDonnell, 2002) and are standard approaches when the end members are distinct (points on a mixing triangle) and bound sample mixtures. In this case, stages green $(\mathrm{G})$, red $(\mathrm{R})$ and dead $(\mathrm{D})$ were end members in the mixing space defined by spectral reflectance vegetation indices normalized difference vegetation index (NDVI) and Red-Green index (RGI). Green trees are green trees of any species, red trees are infected LPP and dead are any dead trees (note that because of the early stage of infestation, dead trees are primarily due to causes other than MPB). We used the indices calculated from the QuickBird image as samples in the mixing space to determine the fraction of each infestation stage (end member) across the image and thus the landscape.

The NDVI (Rouse et al., 1973) and the RGI were used to characterize infestation status. The two indices are defined as

$$
\begin{aligned}
& \mathrm{NDVI}=\left(\frac{\mathrm{NIR}-\mathrm{Red}}{\mathrm{NIR}+\mathrm{Red}}\right) \\
& \mathrm{RGI}=\left(\frac{\text { Green }- \text { Red }}{\text { Green }+ \text { Red }}\right)
\end{aligned}
$$

where NIR, Red and Green are the band values taken from the QuickBird image. NDVI uses reflectance values of near infrared and red bands to designate greenness (a proxy for productivity) on a scale of -1 to 1 . The RGI has been found to discriminate between red and green tree canopies in MPB affected areas (Coops et al., 2006; Hicke and Logan, 2009). We applied the mixing model to the QuickBird image as a series of linear equations: 


$$
\begin{gathered}
f_{\mathrm{G}}+f_{\mathrm{R}}+f_{\mathrm{D}}=1 \\
\mathrm{NDVI}_{\mathrm{QB}}=f_{\mathrm{G}}\left(\mathrm{NDVVI}_{\mathrm{G}}\right)+f_{\mathrm{R}}\left(\mathrm{NDVI}_{\mathrm{R}}\right)+f_{\mathrm{D}}\left(\mathrm{NDVI}_{\mathrm{D}}\right) \\
\mathrm{RGI}_{\mathrm{QB}}=f_{\mathrm{G}}\left(\mathrm{RGI}_{\mathrm{G}}\right)+f_{\mathrm{R}}\left(\mathrm{RGI}_{\mathrm{R}}\right)+f_{\mathrm{D}}\left(\mathrm{RGI}_{\mathrm{D}}\right)
\end{gathered}
$$

where the green-stage fraction $\left(f_{\mathrm{G}}\right)$, red-stage fraction $\left(f_{\mathrm{R}}\right)$ and grey-stage fraction $\left(f_{\mathrm{D}}\right)$ were determined for each $1-\mathrm{m}^{2}$ pixel. $\mathrm{NDVI}_{\mathrm{QB}}$ and $\mathrm{RGI}_{\mathrm{QB}}$ are the vegetation index values calculated for each pixel in the QuickBird image. $\mathrm{NDVI}_{\mathrm{G}, \mathrm{R}, \mathrm{D}}$ and $\mathrm{RGI}_{\mathrm{G}, \mathrm{R}, \mathrm{D}}$ are end members derived from the distributions of the vegetation index values of the field data and the range of the QuickBird data. Any pixels with a negative value for an end member (i.e. lying outside the mixing triangle) were projected back onto the mixing space and calculated as a percentage of the remaining two infestation stages.

A single infestation stage was assigned for each pixel on the basis of the largest fraction of green, red or grey within the pixel. Red-stage pixels were limited to those comprising greater than $50 \%$ red, a threshold based on field observation. The two-sample Kolmogorov-Smirnov (KS) test is a nonparametric statistical test that evaluates differences across the entire frequency distributions of two different populations. It is useful because it is sensitive to differences anywhere in the distribution, not just the median or the extremes. It is also helpful for multivariate comparisons because the KS statistic can be used to gauge the relative importance of different variables (i.e. UAA, slope and energy can be compared using the same scale because KS statistic has 'frequency' units). We used KS tests to determine the maximum vertical difference between two cumulative distribution functions (CDFs) across the three stages of infestation. The differences between infestation stages were found to be statistically significant for each landscape variable ( $p$ values $<<0.05$ ), partially as a function of the large sample size $(n=7482172)$. Therefore, the KS test was used to determine which landscape variables had the largest influences on MPB infestation.

\section{RESULTS}

\section{Spectral library and mixing model}

We determined the average spectral signals for field observed stages of green $(n=245)$, yellow $(n=29)$ and red $(n=58)$ LPP needles and defoliated branches $(n=37)$ (Figure 3). We verified the field classification of infestation status (green, yellow, red or grey) using an unsupervised k-means cluster analysis of the field data (Figure 4). This separated all observations into four mutually exclusive clusters using an iterative process that minimizes the sum of the distances from each spectral signal to the cluster centroid (K-means Clustering, Matlab R2011b, The Mathworks, Inc.). The four k-means clusters closely aligned with the averages from each infestation stage, verifying that the field colour classification was an appropriate way to separate the infestation classes. The yellow cluster was intermediate between green and red stage both in infestation progression, average spectral signal and in spectral indices. Therefore, we reduced the analyses to three infestation stages: G, R, D.

The change in canopy colour due to infestation happens gradually, making the use of two vegetation indices to determine fractions of infestation stages beneficial. The average spectral signals of the three stages of infestation were used to determine which vegetation indices would best separate the infection states for TCEF. In accordance with previous studies (Coops et al., 2006; Hicke and Logan, 2009), we found that NDVI separated green stage from grey stage and RGI separated green stage from red stage (Figure 5).

The mixing model end members were identified using the probability distribution functions of the stages of infestation from the field-based spectral library and their correlation with the two vegetation indices. Three stages were used for classifying infestation: green stage (G) indicated healthy trees, red stage $(R)$ infested trees and grey stage (D) dead trees. We designated the end members bounding the mixing model by using both the average vegetation indices values for each infestation stage and the range of QuickBird values for each vegetation index. The green-stage and grey-stage NDVI end members were the maximum and minimum QuickBird NDVI values, respectively, and the red-stage end member was the average NDVI of red stage from the spectral library. The green-stage and red-stage RGI end members were the maximum and minimum QuickBird values of RGI. Because of the small range of QuickBird RGI values, the grey-stage end member was adjusted on the basis of field verification. The mixing diagram displays the relationship between NDVI, RGI and the infestation stage end members (Figure 6). A composite image of the three fractions demonstrates the spatial variability and pattern of infestation across the watershed (Figure 7).

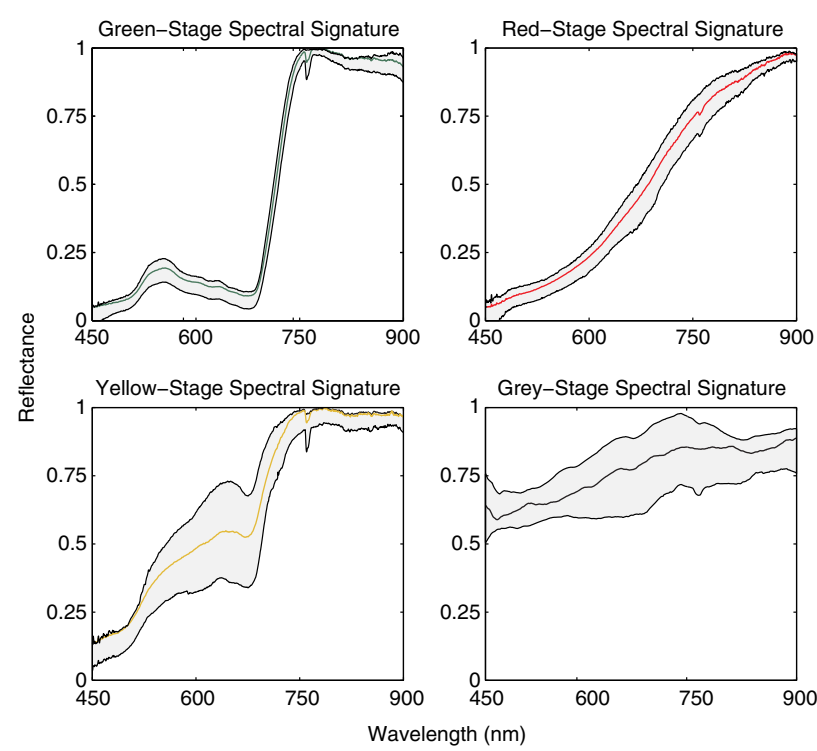

Figure 3. Average spectral signals for each infestation stage based on the spectral library derived from field data. Regions shaded in grey show one standard deviation from the mean indicated by bold line. These show the spectral differences between each stage of infestation, although the yellow stage is distinct from the other three stages of infestation, it could not be separated in the mixing model because of it being an intermediate of green stage and red stage. 


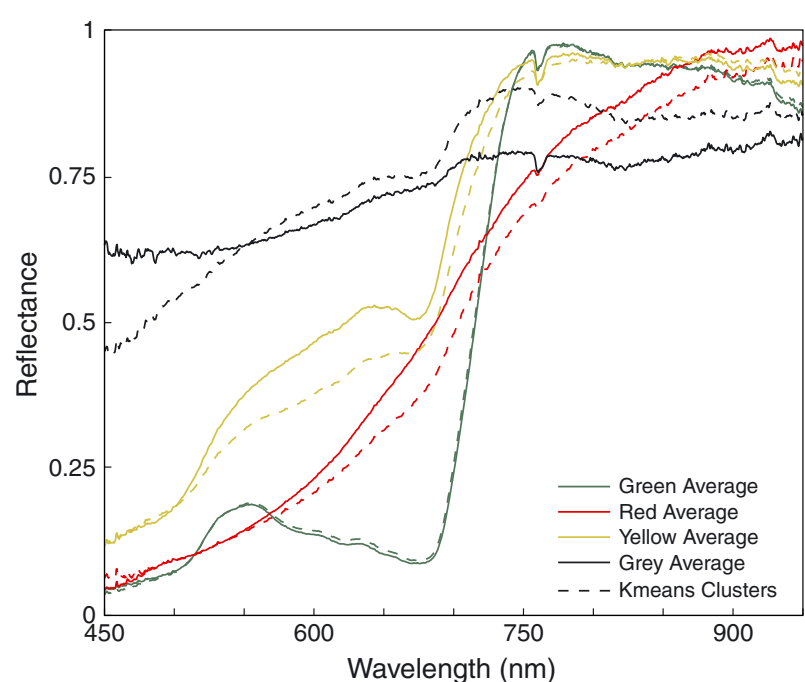

Figure 4. Average spectral signal for each infestation stage and associated k-means centroid. Unsupervised k-means cluster analysis corroborated that the field classification was an appropriate way to classify the samples.

\section{Landscape analyses and infestation stage assessment}

Approximately $2 \%$ of pixels in TCEF with vegetation over $3 \mathrm{~m}$, excluding managed areas, were red stage in 2010 . We analysed eight landscape variables to determine relationships between red-stage pixels and their associated landscape and forest structure metrics. The KS test revealed differences in the CDFs between each infestation stage for each landscape variable (Table 1). The lowest KS values (i. e. the least significant and smallest differences) were found between the distributions of green-stage and grey-stage pixels. Red-stage pixel landscape positions were significantly different from green-stage and grey-stage pixel landscape positions (Figure 8). The landscape variable showing the greatest difference between the red stage and green stage was vegetation density, with red-stage pixels found in locations with lower vegetation density. The next largest differences between red-stage and green-stage pixels were found in the slope, aspect and insolation distributions. The red-stage pixels were found in locations with steeper slopes, more southerly aspects and higher insolation than the green and grey-stage pixels. Red-stage pixels were also more frequently found in lower elevations and in areas with lower TWI and UAA values and shorter tree heights than green-stage pixels.

\section{DISCUSSION}

Assessing the spatial intersection of MPB infestation with topographic and vegetation characteristics can provide insight into the factors that facilitate or impede infestation and outbreaks. Because these factors manifest across a range of spatial and temporal scales and are interrelated, organizing them into a hierarchical structure has previously been difficult. Drivers include abiotic and biotic stressors, climate dynamics, beetle and host physiology, vegetation density and water availability. These drivers combine and interact to exert strong controls over disturbance patterns and outbreak dynamics across the landscape.

We found that during the 2010 MPB infestation at TCEF, exploited host trees were more often located in areas of higher vegetation water stress that resulted from shorter vegetation or relatively dry landscape positions. These results suggest that topographic redistribution of water and topographically influenced energy availability interact with vegetation characteristics to affect spatial patterns of forest disturbances such as MPB infestation. Although our results suggest that certain landscape positions were more susceptible to MPB infestation than others during early stages of an outbreak, we also emphasize the general importance of landscape characterization for understanding how ecohydrological processes manifest at watershed scales.

We quantified relationships between topographic and vegetation variables and infestation stages to infer which
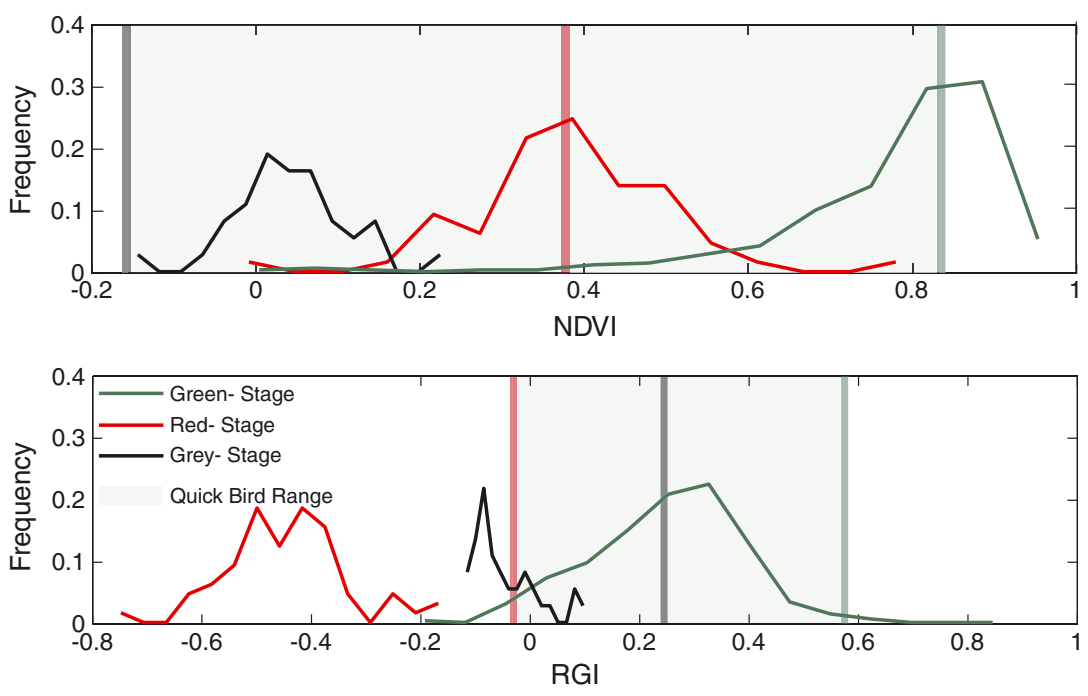

Figure 5. Frequency distributions of vegetation indices for each infestation stage represented in the mixing model. The stage of each sample in the spectral signal library was based on field classification. End members, denoted by vertical bars in their respective colours, were chosen based on the distributions of each stage in the spectral library and by the extent of the QuickBird values for each index. 


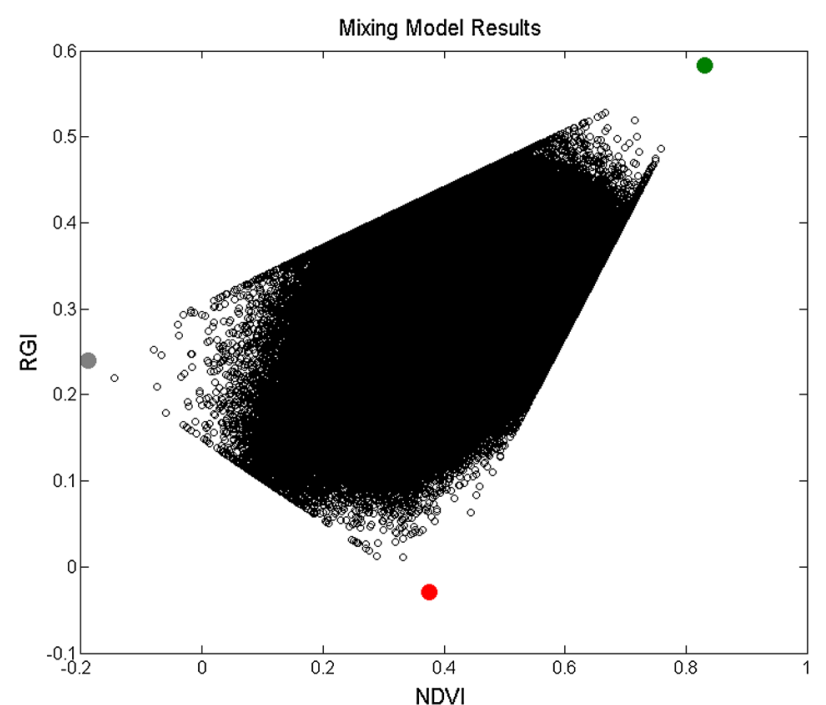

Figure 6. Mixing diagram; each black circle represents one Quick Bird pixel. End members are denoted by their respective colours. Sharp edges are due to orthogonal projection of some samples that fell outside of the triangle onto the triangle.

variables exert the strongest controls over MPB infestation patterns (Figure 8). In these CDFs, greater divergence of one curve from the next indicates strong differences between infestation stages with regard to the terrain metric of interest (Figure 8). Conversely, each of the CDFs overlaying one another indicates little difference between infestation stages in relation to the metric. For instance, the green-stage and grey-stage pixels had little difference in their distributions in relation to many of the landscape variables, corroborating the spatial heterogeneity expected for live and previously dead trees in an undisturbed landscape (i.e. random distribution). However, the distribution of red-stage trees demonstrated different patterns across the landscape in relation to terrain metrics. In TCEF, trees in locations with lower vegetation density, steeper slopes, south eastern aspects, higher insolation, lower UAA, lower TWI, lower elevation and shorter tree
Table I. Kolmogorov-Smirnov statistics for all landscape variables.

\begin{tabular}{lccc}
\hline & Green-red & Grey-red & Green-grey \\
\hline Forest density & $0 \cdot 24$ & 0.28 & 0.07 \\
Aspect & $0 \cdot 19$ & 0.27 & 0.08 \\
Insolation & $0 \cdot 17$ & 0.24 & 0.07 \\
Slope & $0 \cdot 16$ & 0.18 & 0.04 \\
Elevation & 0.14 & 0.12 & 0.09 \\
TWI & $0 \cdot 13$ & $0 \cdot 10$ & 0.04 \\
Vegetation height & 0.07 & 0.09 & 0.03 \\
UAA & 0.05 & 0.03 & 0.03 \\
\hline
\end{tabular}

These values are the maximum vertical difference between the cumulative distribution functions; higher values indicate greater divergence between infestation stage distributions. TWI is the topographic wetness index that incorporates local slope and UAA (upslope accumulated area), both proxies for water availability based on topography.

height were more frequently impacted by the recent MPB infestation than trees in other locations (Figure 8; Tables 2 and 3 ).

Forest density has been the focus of many MPB studies because of its relevance to forest management and its influence on pheromone dispersal and beetle infestation patterns. Our results indicate greater infestation in locations with less dense forest. These results could be attributed to density effects on growth rates and phloem thickness of those trees (Amman, 1977; Shore and Safranyik, 1992) and/or the potential increase in pheromone concentration in these less dense locations as they escape from the surrounding dense forest. Pheromone transport dynamics influence infestation patterns because beetles use them to recruit others to mass attack specific hosts. In dense forests, beetle pheromone plumes are trapped beneath the canopy, until flowing to an opening in the canopy where solar energy heats the ground and adjacent air carries the pheromones up and out of the canopy (Fares et al., 1980).

Although we confined our analysis to intact forest, TCEF has a range of basal areas (i.e. forest densities) with

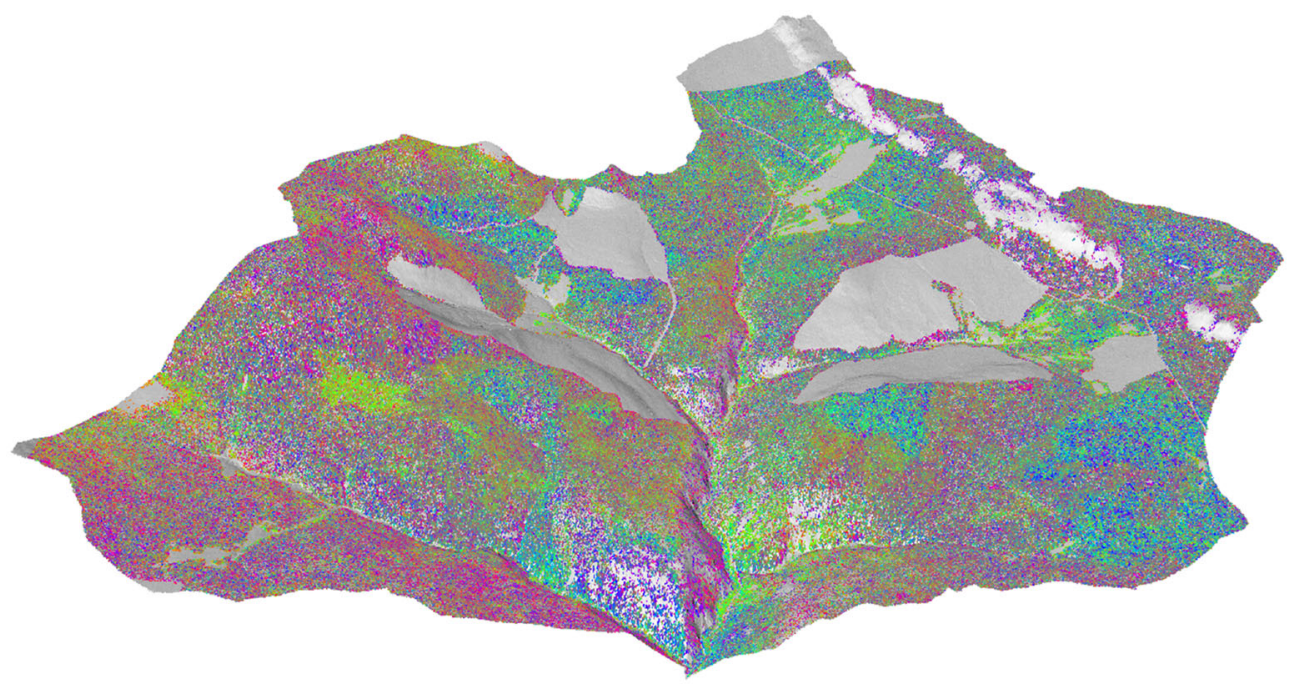

Figure 7. False-colour map showing the composite mixing model results. Any pixel over $30 \%$ fraction red appears as a mixture of red, which visually exaggerates the amount of infestation in the watershed $(2 \%)$. This map shows higher infestation in specific areas of the watershed indicating topographical and hydrological influences on infestation, such as southerly slopes. 

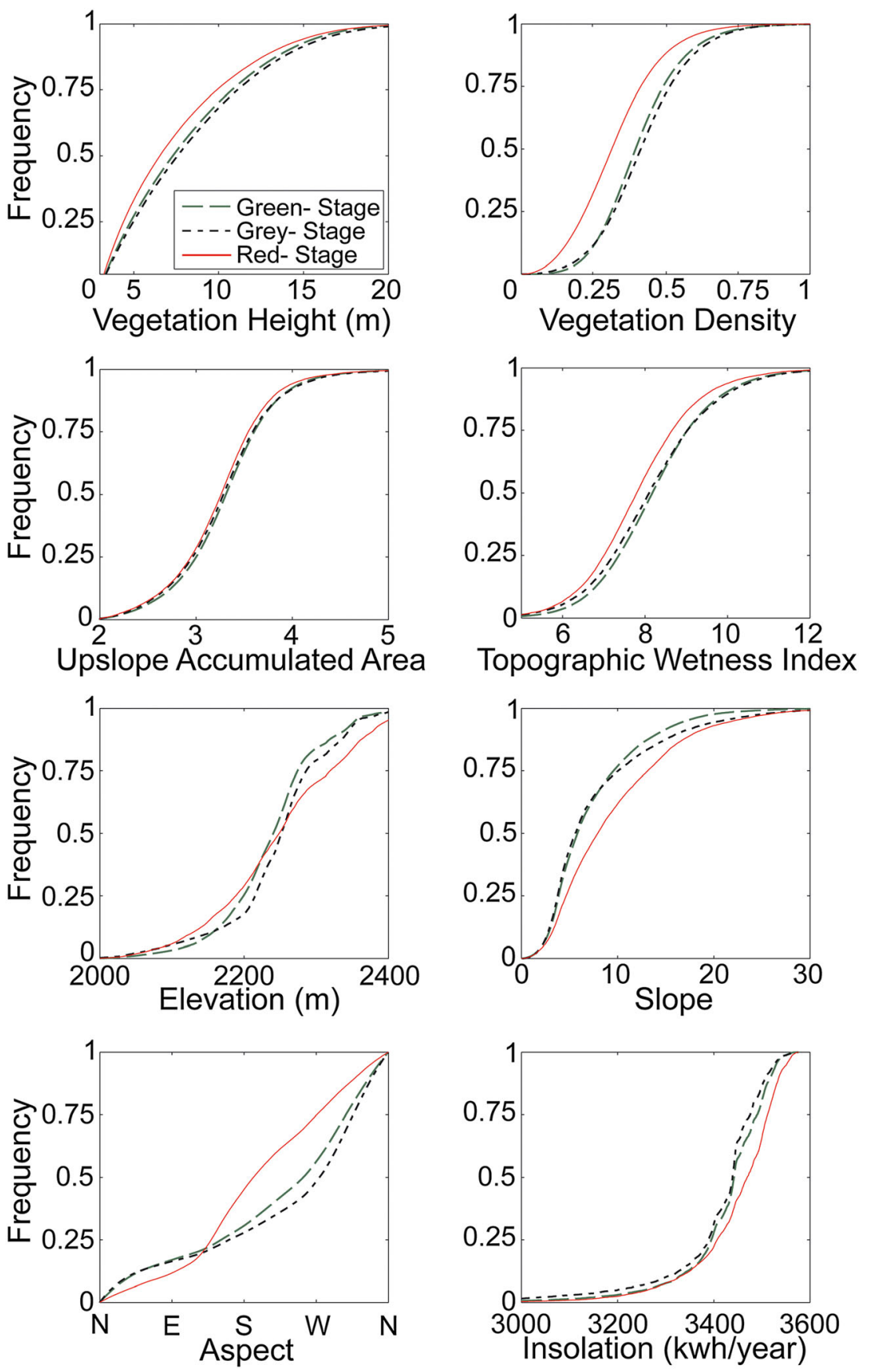

Figure 8. Cumulative distribution functions (CDFs) of each landscape variable for each infestation stage. These CDFs show the values of each landscape variable where red-stage trees deviate from landscape positions occupied by healthy trees. The larger the deviation between curves indicates larger differences in the landscape positions occupied by those infestation stage.

some being as low as the thinned treatments in the studies of Schmitz et al. (1989) and Mitchell et al. (1983). We excluded managed stands from our analysis, but anecdotal observations suggested little infestation within patch cuts. This could be due to increased resource availability in managed stands versus the potential lack of resources that has lead to less dense locations in the unmanaged forest. In less dense locations, isolated trees have larger crowns and are likely to have less competition thereby allowing for thicker, potentially more nutritious, phloem (Safranyik, 1968). Although thicker, more nutritious phloem is directly related to increased beetle production (Amman, 1972), thinning treatments have been found to reduce tree mortality because of MPB (Mitchell et al., 1983; Schmitz et al., 1989), with the purported mechanism of increased host resistance from the increased photosynthetically active leaf area. Thinning also increases wind and incoming solar radiation, potentially dispersing beetle pheromones out of the stand more effectively.

Beetle population density and physiological characteristics of the host are important competing factors influencing tree infestation. In our study, we found greater infestation in smaller trees (i.e. younger; note, trees under $3 \mathrm{~m}$ were not included in our analysis; shorter trees above the threshold are indicative of trees that have at least $3.3 \mathrm{~cm}$ diameter at breast height) suggesting that the beetle 
Table II. Means of each infestation variable classified by infestation stage.

\begin{tabular}{lccc}
\hline & Green & Grey & Red \\
\hline Forest density & 0.41 & 0.42 & 0.33 \\
Aspect (degrees) & 221.15 & 231.59 & 197.42 \\
Insolation (kwh/year) & 3426.7 & 3411.5 & $3446 \cdot 8$ \\
Slope (degrees) & $7 \cdot 34$ & $7 \cdot 83$ & 9.52 \\
Elevation (m) & $2238 \cdot 2$ & $2247 \cdot 1$ & $2248 \cdot 6$ \\
TWI (ln[ha]) & 8.25 & $8 \cdot 18$ & 7.88 \\
Vegetation height (m) & 8.18 & 8.45 & 7.59 \\
UAA (ha) & 3.31 & 3.29 & 3.25 \\
\hline
\end{tabular}

Despite relatively small differences between means, full distributions display noticeable differences between infestation stages (Figure 8). Forest density is the frequency of treed pixels.

TWI, topographic wetness index; UAA, upslope accumulated area.

Table III. Differences between mean values of landscape variables based on infestation stage.

\begin{tabular}{lccc}
\hline & Green-red & Grey-red & Green-grey \\
\hline Forest density & 0.08 & 0.09 & -0.01 \\
Aspect (degrees) & 23.73 & 34.17 & -10.43 \\
Insolation (kwh/year) & $-20 \cdot 1$ & $-35 \cdot 3$ & $15 \cdot 2$ \\
Slope (degrees) & $-2 \cdot 18$ & -1.68 & -0.50 \\
Elevation (m) & -10.4 & -1.5 & -8.9 \\
TWI (ln[ha]) & 0.37 & 0.30 & 0.07 \\
Vegetation height (m) & 0.60 & 0.86 & -0.26 \\
UAA (ha) & 0.06 & 0.04 & 0.02 \\
\hline
\end{tabular}

Forest density is the frequency of treed pixels.

TWI, topographic wetness index; UAA, upslope accumulated area.

population in TCEF has not reached the incipient epidemic infestation stage where their population size is able to overcome the defences of healthy tall trees. Our acquisition of QuickBird imagery at an early stage of infestation allowed us to observe which trees were first infested with an endemic (small population size), which could lead to an incipient epidemic population (large enough to mass attack a large diameter tree; Safranyik, 2003). In general, once beetles reach this epidemic threshold, they are able to overcome the defences of larger healthier trees, thereby potentially masking correlations to landscape position and host properties (Berryman, 1982).

The topographic positions where we observed red-stage pixels are associated with decreased water availability. Steep slopes, low UAA and low TWI facilitate the drainage of water away from these landscape positions, and south facing slopes are associated with greater insolation and increased potential evapotranspiration. These results are consistent with the general findings of other MPB research (Amman, 1973; Safranyik and Carroll, 2006). Specifically, drier landscape positions can decrease host defences because water stress may diminish photosynthesis and carbon metabolism necessary for resin production. Higher insolation further contributes to water stress in those landscape positions because of increased potential evapotranspiration. Increased infestation in lower elevation landscape positions corresponds with other findings
(Amman, 1973) and is thought to be due to warmer winter conditions that allow for increased attack establishment and brood survival the following year. It has been shown that water stressed trees are more often found on south facing slopes (Safranyik and Carroll, 2006). At TCEF, south-easterly slopes were the most impacted by the current infestation.

\section{IMPLICATIONS}

Identifying areas most at risk for MPB infestation needs to include assessment of multiple landscape variables. When considering the combined effects of tree height, density and water availability, smaller trees may have less extensive root systems than larger trees (Drexhage and Gruber, 1999) and may experience even more water stress than larger trees because of their limited access to soil moisture during the relatively arid growing season. Although treatments such as thinning might be an option to reduce further MPB infestation, water availability is not equally distributed across the landscape and should be evaluated when determining the location of likely initial susceptibility and subsequent treatments.

In addition to ecohydrological processes that influence the pattern of MPB disturbance, changes in canopy and ground cover from such disturbances can also have strong influences on ecohydrological processes in watersheds (Turner, 2005). This ecohydrological feedback can strongly influence watershed water balances, biogeochemical cycling and resultant water quality. Tree mortality could initially result in decreased plant uptake of water and nutrients, and the spatial location, pattern and distribution of infestation may affect transport and availability of these resources. High mortality rates in low-density areas of the watershed could lead to increased snowpack accumulation, increased throughfall and decreased transpiration.

The lack of trees in close proximity to red-stage trees could make more water and nutrients available for vegetation downslope because of a lack of compensatory uptake. Tree mortality in low water availability locations could have a muted influence on the catchment water balance and water quality because drier landscape positions typically have less influence on stream water composition because of decreased connectivity (Jencso and McGlynn, 2011). Tree mortality on southerly aspects and high insolation locations could increase evaporation more so than in less insolated locations and result in equivocal effects on the soil water balance. Variably of decreased or increased soil moisture within the watershed could also have nonlinear effects on fluxes of trace gases such as $\mathrm{CO}_{2}$, $\mathrm{N}_{2} \mathrm{O}$ and $\mathrm{CH}_{4}$ from soils (Riveros-Iregui et al., 2011b). Changes in the distribution, quantity and quality of fuel following MPB-related disturbance may also exert a strong influence on fire potential (Safranyik and Carroll, 2006).

It is important to consider that disturbances such as an MPB outbreak are likely to induce nonlinear watershed responses involving both threshold behaviour and feedbacks between the biological and physical components of the system. There may exist infestation thresholds below 
which effects on watershed-scale hydrological or biogeochemical processes are not easily observable, for example, variability of net primary productivity after disturbance is affected by the severity of the outbreak (Hicke et al., 2012; Pugh and Gordon, 2012). MPB-related disturbances may induce stand regeneration and growth responses from surviving trees, potentially augmenting the functions of the dead trees. Our results highlight the need for further study of watershed-scale disturbances to evaluate the complex feedbacks between landscape structure (i.e. topographic redistribution of water) and forest ecosystem dynamics.

\section{CONCLUSION}

We demonstrated that MPB-infested trees were more often found in drier landscape positions during the early stage of an MPB outbreak. We used QuickBird satellite imagery and LiDAR to quantify beetle infestation stages, identify the specific locations more and less impacted in the watershed and characterize their relationship to forest and landscape variables. We found that topographic and forest structure variables helped to explain early infestation patterns across the landscape. We found that smaller trees, trees located in lower density forest stands and trees in drier landscape positions were more likely to be infested than other trees. Our results correspond with prior research on outbreak dynamics (Amman, 1972; Amman, 1973; Safranyik, 2003), while furthering understanding of how ecological and hydrological processes interact with each other at high spatial resolution to influence the pattern of insect infestation at the landscape scale.

The TCEF appears to be at an early stage of MPB outbreak with smaller trees, in lower density forest stands and in drier landscape positions experiencing greater MPB infestation. As more trees become infested, we suggest that the spatial pattern heretofore observed could be amplified or as the infestation progresses, the beetle population could overwhelm tree defences regardless of landscape and forest stand characteristics. Further research on how hydrological and ecological processes will change as a result of beetle infestation is necessary to develop a more comprehensive understanding of the implications of MPB-induced tree mortality. This study could be combined with future research to inform management decisions and allow spatial and temporal targeting of control measures. A processbased understanding of these dynamics across landscape positions will be necessary to scale from plot to watershed extents and to determine how landscape structure and the spatial pattern of disturbance interact to control the evolution of complex watershed ecohydrologic systems.

\section{ACKNOWLEDGEMENTS}

Special thanks to Galen Laird, Rebecca Kurnick and Anna Bergstrom for the help with field work and to Fabian Nippgen, John Mallard and Tim Covino for technical help throughout the project. We would also like to thank the Undergraduate Scholars Program, US
Forest Service, NSF award DEB-1110742 for funding the hand-held spectrometer and EAR-0838193 for the Quick Bird, NSF grant EAR 0837937, NSF grant EAR $0404130 \mathrm{NSF}$, and grant EAR 0943640.

\section{REFERENCES}

Allen CD, Macalady AK, Chenchouni H, Bachelet D, McDowell N, Vennetier M, Kitzberger T, Rigling A, Breshears DD, Hogg EH, Gonzalez P, Fensham R, Zhang Z, Castro J, Demidova N, Lim J, Allard G, Running SW, Semerci A, Cobb N. 2010. A global overview of drought and heat-induced tree mortality reveals emerging climate change risks for forests. Forest Ecology and Management 259(4): 660-684. DOI: http://dx. doi.org/10.1016/j.foreco.2009.09.001.

Amman GD. 1972. Mountain, and Pine Beetle Production in relationship to Thickness of Lodgepole Pine Phloem Rep., USDA Forest Service, Ogden, Utah 84401. 259(4): 660-684. DOI: http://dx.doi.org/10.1016/j. foreco.2009.09.001.

Amman GD. 1973. Population Changes of the Mountain Pine Beetle in Relation to Elevation. Environmental Entomology: 2(4): 541-548.

Amman G. 1977. Role of the mountain pine beetle in lodgepole pine ecosystems: impact on succession. In The Role of Arthropods in Forest Ecosystem, Mattson WJ (ed.). Springer-Verlag: New York; 3-18.

Amman GD, McGregor MD, Dolph RE. 1985. Forest insect \& disease leaflet 2, reprinted 1990. Mountain Pine Beetle, USDA Katharine A. Sheehan (ed.) Revised for the Internet September 1997. USDA Forest Service, Pacific Northwest Region, Natural Resources: Portland Oregon.

Berryman AA. 1982. Population dynamic of bark beetles. In Bark Beetles in North American Conifers: A system for the study of evolutionary biology, Sturgeon JBM (ed.). University of Texas Press: Austin, Texas; 264-314.

Beven KJ, Kirkby MJ. 1979. A physically based, variable contributing area model of basin hydrology. Hydrological Sciences Bulletin 24(1): 43-69.

Boehner J, Antonic O. 2009. Land Surface Parameters Specific to TopoClimatology. In Geomorphometry Concepts, Software, Applications, Hengl T, Reuter HI (ed.). Developments in Soil Science, 33, Elsevier: Amsterdam; 227-254.

Boon S. 2007. Snow accumulation and ablation in a beetle-killed pine stand, northern Interior British Columbia. BC Journal of Ecosystems and Management 8(3): 1-13.

British Columbia Ministry of Forests and Range. 2011. Beetle Facts, edited.

Burns DA, McDonnell JJ, Hooper RP, Peters NE, Freer JE, Kendall C, Beven K. 2001. Quantifying contributions to storm runoff through endmember mixing analysis and hydrologic measurements at the Panola Mountain Research Watershed (Georgia, USA). Hydrological Processes 15: 1903-1924.

Clow DW, Rhoades C, Briggs J, Caldwell M, Lewis WM Jr. 2011. Responses of soil and water chemistry to mountain pine beetle induced tree mortality in Grand County, Colorado, USA. Applied Geochemistry 26(Supplement 0): S174-S178.

Coops NC, Johnson M, Wulder MA, White JC. 2006. Assessment of QuickBird high spatial resolution imagery to detect red attack damage due to mountain pine beetle infestation. Remote Sensing of Environment 103(1): 67-80.

Dennison PE, Brunelle AR, Carter VA. 2010. Assessing canopy mortality during a mountain pine beetle outbreak using GeoEye-1 high spatial resolution satellite data. Remote Sensing of Environment 114(11): 2431-2435.

DeWalle DR, Swistock BR, Sharpe WE. 1988. Three-component tracer model for stormflow on a small Appalachian forested catchment. Journal of Hydrology 104: 301-310.

Drexhage M, Gruber F. 1999. Above- and Below-stump Relationships for Picea Abies: Estimating Root System Biomass from Breast-height Diameters. Scandinavian Journal of Forest Research 14(4): 328-333.

Emanuel RE, Epstein HE, McGlynn BL, Welsch DL, Muth DJ, P D'Odorico. 2010. Spatial and temporal controls on watershed ecohydrology in the northern Rocky Mountains. Water Resources Research 46(14): W11553. DOI:10.1029/2009WR008890.

Emanuel RE, Riveros-Iregui DA, McGlynn BL, Epstein HE. 2011. On the spatial heterogeneity of net ecosystem productivity in complex landscapes. Ecosphere 2(7); art86. DOI:10.1890/ES11-00074.1.

Fares Y, Sharpe PJH, Magnuson CE. 1980. Pheromone dispersal in forests. Journal of Theoretical Biology 84: 335-359. 
Farnes PE, Shearer RC, McCaughey WW, Hanson KJ. 1995. Comparisons of Hydrology, Geology and Physical Characteristics between Tenderfoot Creek Experimental Forest (East Side) Montana, and Coram Experimental Forest (West Side) Montana Final Report RJVA-INT92734, I. R. S. USDA Forest Service (ed.). Forestry Sciences Laboratory: Bozeman, Montana; 19.

Furniss MM, Furniss RL. 1972. Scolytids (coleoptera) on snowfields above timberline in oregon and washington. Canadian Entomologist 104(9): 1471-1478.

Gannon A, Sontag S. 2009. Montana Forest Insect and Disease Conditions and Program Highlights- 2010, F. S. U.S. Department of Agriculture, Region 1 Norhtern Region (ed.). Montana Department of Natural Resources and Conservation Forestry Division, US Forest Service: Helena, MT.

Gannon A, Sontag S. 2011. Montana Forest Insect and Disease Conditions and Program Highlights- 2010, F. S. U.S. Department of Agriculture, Region 1 Norhtern Region (ed.). Montana Department of Natural Resources and Conservation Forestry Division, US Forest Service: Helena, MT.

Hardy CC, Smith HY, McCaughey W. 2006. The use of silviculture and prescribed fire to manage stand structure and fuel profiles in a multiaged lodgepole pine forest. Paper presented at Fuels management- how to measure sucess. United States Department of Agriculture, Forest Service, Rocky Mountain Research Station, Fort Collins, Colorado.

Hicke JA, Logan J. 2009. Mapping whitebark pine mortality caused by a mountain pine beetle outbreak with high spatial resolution satellite imagery. International Journal of Remote Sensing 30(17): 4427-4441.

Hicke JA, Allen CD, Desal AR, Dietze ME, Hall RJ, Hogg EH, Kashian DM, Raffa KF, Sturrock RN, Vogelmann J. 2012. Effects of biotic disturbances on forest carbon cycling in the United States and Canada. Global Change Biology 18(1): 7-34. DOI: 10.1111/j.13652486.2011.02543.x.

Hilker T, Coops NC, Coggins SB, Wulder MA, Brown M, Black TA, Nesic Z, Lessard D. 2009. Detection of foliage conditions and disturbance from multi-angular high spectral resolution remote sensing. Remote Sensing of Environment 113(2): 421-434.

Holdorf HD. 1981. Soil Resource Inventory, Lewis and Clark National Forest-Interim In-Service Report, U. F. Service (ed.). Lewis and Clark National Forest, Forest Supervisor's Office: Great Falls, MT.

Huete AR. 1988. A soil-adjusted vegetation index (SAVI). Remote Sensing of Environment 25(3): 295-309.

Jencso KG, McGlynn BL. 2011. Hierarchical controls on runoff generation: Topographically driven hydrologic connectivity, geology, and vegetation. Water Resources Research. DOI: 10.1029/2011WR010666.

Jencso KG, McGlynn BL, Gooseff MN, Wondzell SM, Bencala KE, Marshall LA. 2009. Hydrologic connectivity between landscapes and streams: Transferring reach and plot scale understanding to the catchment scale. Water Resources Research 45: W04428. DOI: 10.1029/2008WR007225.

Jencso KG, McGlynn BL, Gooseff MN, Bencala KE, Wondzell SM. 2010. Hillslope hydrologic connectivity controls riparian groundwater turnover: Implications of catchment structure for riparian buffering and stream water sources. Water Resources Research 46: W10524. DOI: 10.1029/2009WR008818.

Kurz WA, Dymond CC, Stinson G, Rampley GJ, Neilson ET, Carroll AL, Ebata T, Safranyik L. 2008. Mountain pine beetle and forest carbon feedback to climate change. Nature 452(7190): 987-990.

Mathre DE. 1964. Pathogenicity of Ceratocystis ips and Ceratocystis minor to Pinus ponderosa. Boyce Thompson Inst.: Rocky Mountain Forest and Range Experiment Stations, Fort Collins, CO.

McCaughey WW. 1996. Tenderfoot creek experimental forest. In Experimental Forests, Ranges, and Watersheds in the Northern Rocky Mountains: A Compendium of Outdoor Laboratories in Utah, Idaho, and Montana, U. S. D. O. A., Schmidt WC, Friede JL (eds). Forest Service: Utah.

McCaughey WW, Martin SJ, Blomquist DA. 2006. Two-aged Silvicultural Treatments in Lodgepole Pine Stands Can Be Economically Viable. Fort Collins, CO: U.S. Department of Agriculture, Forest Service, Rocky Mountain Research Station. 7 p. U.S. Department of Agriculture (ed.). Rocky Mountain Research Station: Fort Collins, CO.

McGlynn BL, McDonnell JJ. 2002. Quantifying the relative contributions of riparian and hillslope zones to catchment runoff and composition. Water Resources Research, 39(1310): 20. DOI: 10.1029/2003WR002091.

Mincemoyer SA, Birdsall JL. 2006. Vascular flora of the tenderfoot creek experimental forest, Little Belt Mountains, Montana. Madrono 53(3): 211-222.

Mitchell RG, Waring RH, Pitman GB. 1983. Thinning lodgepole pine increases tree vigor and resistance to mountain pine-beetle. Forest Science 29(1): 204-211.
Ogunkoya OO, Jenkins A. 1993. Analysis of storm hydrograph and flow pathways using a three-component hydrograph separation model. Journal of Hydrology 142(1-4): 71-88.

Oke TR. 1988. Boundary Layer Climates, 2nd edn. Taylor \& Francis: London.

Peterman RM. 1978. The ecological role of mountain pine beetle in lodgepole pine forests. Paper presented at Theory and Practice of Mountain Pine Beetle Management in Lodgepole Pine Forests, Pullman, WA, April 25-27.

Pugh E, Gordon E. 2012. A conceptual model of water yield impacts from beetle-induced tree death in snow-dominated lodgepole pine forests. Hydrological Processes. DOI: 10.1002/hyp.9312.

Pugh E, Small E. 2011. The impact of pine beetle infestation on snow accumulation and melt in the headwaters of the Colorado River. Ecohydrology. DOI: 10.1002/eco.239.

Raffa KF, Berryman AA. 1983. The Role Of Host Plant-Resistance In The Colonization Behavior And Ecology Of Bark Beetles (Coleoptera, Scolytidae). Ecological Monographs 53(1): 27-49.

Raffa KF, Berryman AA. 1987. Interacting selective pressures in coniferbark beetle systems - a basis for reciprocal adaptations. American Naturalist 129(2): 234-262.

Raffa KF, Aukema BH, Bentz BJ, Carroll AL, Hicke JA, Turner MG, Romme WH. 2008. Cross-scale drivers of natural disturbances prone to anthropogenic amplification: The dynamics of bark beetle eruptions. Bioscience 58(6): 501-517.

Riveros-Iregui DA, Hu J, Burns SP, Bowling DR, Monson RK. 2011a. An interannual assessment of the relationship between the stable carbon isotopic composition of ecosystem respiration and climate in a high-elevation subalpine forest. Journal of Geophysical ResearchBiogeosciences 116: G02005. DOI:10.1029/2010JG001556.

Riveros-Iregui DA, McGlynn BL, Marshall LA, Welsch DL, Emanuel RE, Epstein HE. 2011b. A watershed-scale assessment of a process soil CO(2) production and efflux model. Water Resources Research 47: W00J04. DOI: 10.1029/2010WR009941.

Rodriguez-Iturbe I. 2000. Ecohydrology: A hydrologic perspective of climate-soil-vegetation dynamics. Water Resources Research 36(1): 3-9.

Rouse JW, Haas RH, Shell JA, Deering DW. 1973. Monitoring vegetation systems in the Great Plains with ERTS-1. Paper presented at Third Earth Resources Technology Satellite Symposium, Washington, D.C.

Safranyik L. 1968. Development of a technique for sampling mountain pine beetle populations in lodgepole pine. The University of British Columbia, Vancouver; 195 pp.

Safranyik L. 2003. Mountain Pine Beetle in Lodgepole Pine. Paper presented at Mountain Pine Beetle Symposium: Challenges and Solutions, National Resources Canada, Canadian Forest Service Pacific Forestry Centre, Kelowna, British Columbia.

Safranyik L, Carroll AL. 2006. The biology and epidemiology of the mountain pine beetle in lodegpole pine forests. Victoria, BC Canada.

Safranyik L, Shrimpton DM, Whitney HS. 1975. An interpretation of the interaction between lodgepole pine, the mountain pine beetle and its associated blue stain fungi in western Canada. Paper presented at Management of Lodgepole Pine Ecosystems, Pullman, Washington, Washington State University.

Schmitz RF, McGregor MD, Amman GD, Oakes RD. 1989. Effect of partial cutting treatments of lodgepole pine stands on the abundance and behavior of flying mountain pine beetles. Canadian Journal of Forest Research 19: 566-574.

Shepherd RF. 1966. Factors influencing the orientation and rates of activity of Dendroctonus ponderosae Hopkins (Coleoptera: Scolytidae). Canadian Entomologist 98: 507-518.

Shore TL, Safranyik L. 1992. Susceptibility and risk rating systems for the mountain pine beetle in lodgepole pine stands; $9 \mathrm{pp}$.

Shore TL, Safranyik L, Whitehead RJ. 2006. Principles and Concepts of Management. Paper presented at The Mountain Pine Beetle A Synthesis of Biology, Management, and Impacts on Lodgepole Pine. Natural Resources Canada, Canadian Forest Service, Pacific Forestry Centre, Victoria, BC.

Taylor SW, Carroll AL, Alfaro RI, Safranyik L. 2006. Forest, climate and mountain pine beetle outbreak dynamics in western Canada; 67-94.

Turner MG. 2005. Landscape ecology in North America: Past, present, and future. Ecology 86(8): 1967-1974.

Wilson JP, Gallant JC. 2000. Terrain Analysis: Principles and Applications. John Wiley and Sons, Inc.: New York.

Wulder MA, Dymond CC, White JC, Leckie DG, Carroll AL. 2006. Surveying mountain pine beetle damage of forests: A review of remote sensing opportunities. Forest Ecology and Management 221(1-3): $27-41$. 